found no difference in the proportion of surgical or nephrology centres that provided skin cancer surveillance, full skin examination, or specific training for clinicians performing surveillance (table), regardless of the size of the unit (data not shown).

\section{Comment}

Skin cancer surveillance is available only to a minority of UK renal transplant recipients. We found no difference between surveillance strategies in surgical and nephrology centres.

Surveillance of individuals with atypical mole syndrome in the general population is well established. Such people have an estimated cumulative 10 year risk of melanoma of $11 \%$, compared with a $32 \%$ prevalence of non-melanoma skin cancer in transplant recipients. ${ }^{1}$ Guidelines for annual screening of renal transplant recipients for non-melanoma skin cancer were recently established in the United States. ${ }^{3}$ We previously showed the benefit of nurse led surveillance in the United Kingdom, which facilitates earlier diagnosis and treatment of non-melanoma skin cancer, with a potential reduction in morbidity and mortality. ${ }^{2}$ Clinicians doing surveillance must have adequate training to maintain clinical competence; current levels of training are inadequate. Non-melanoma skin cancer often occurs on covered body sites ( $20 \%$ of cases ${ }^{1}$ ); such lesions could be missed in centres doing only limited skin examination.

Although advice and literature on avoidance of ultraviolet light are given at the time of transplantation, only a minority of patients remain aware of the risks and adopt adequate sun protection measures long term. ${ }^{5}$ Education of patients should start as soon as transplantation is recognised as a potential treatment and should continue long term.
All transplant recipients should have skin cancer surveillance, and all clinicians (general practitioners, specialist physicians and surgeons, and nurses) caring for transplant recipients should be aware of the risks. The higher prevalence of non-melanoma skin cancer in renal transplant recipients compared with the general population is largely due to long term immunosuppression. The prevalence of skin cancer is therefore also likely to be increased in patients taking immunosuppression for a range of non-renal clinical conditions.

We thank all of the nephrologists, transplant surgeons, specialist nurses, and transplant coordinators throughout the United Kingdom who completed and returned the questionnaires.

Contributors: PNH conceived and designed the study, wrote the draft manuscript, and is the guarantor for the paper. SMR distributed the questionnaires and liaised with individual units. AAF did the statistical analyses and collated the database. AGS advised on dermatological aspects of the study. HMR helped to design the study. AAF, AGS, and HMR reviewed the draft and final versions of the manuscript

Funding: Lord Trafford award from the Royal College of Nursing.

Competing interests: None declared.

1 Ramsay HM, Fryer AA, Reece S, Smith AG, Harden PN. Clinical risk factors associated with nonmelanoma skin cancer in renal transplant recipients. Am J Kid Dis 2000;36:167-76.

2 Harden PN, Fryer AA, Reece S, Smith AG, Ramsay HM. Annual incidence and predicted risk of nonmelanoma skin cancer in renal transplant recipients. Transplant Proceedings 2001;33:1302-4.

3 Kasiske BL, Vazquez MA, Harmon WE, Brown RS, Danovitch GM, Gaston RS, et al. Recommendations for the outpatient surveillance of renal transplant recipients. J Am Soc Nephrol 2000;11:S1-86.

4 Salopeck TG, Rigel DS, Kopf AW, Bart RS. Atypical mole syndrome: risk factor for cutaneous malignant melanoma and implications for management. J Am Acad Dermatol 1995;32:479-94.

5 Seukeran DC, Newstead CG, Cunliffe WJ. The compliance of renal transplant recipients with advice about sun protection measures. Br J Dermatol 1997;138:301-3.

(Accepted 18June 2001)

\title{
Seasonal variations in hospital admission for deep vein thrombosis and pulmonary embolism: analysis of discharge data
}

\author{
Fabrice Boulay, Frédéric Berthier, Grégory Schoukroun, Charles Raybaut, Yves Gendreike, \\ Bruno Blaive
}

Seasonal variation in fatal pulmonary embolism has been well documented by at least 23 reports comprising nearly 11000 cases. $^{1}$ Evidence is lacking, however, for seasonal variation in deep vein thrombosis-the only large hospital series available did not establish significant variation. ${ }^{2}$ We analysed hospital admissions for deep vein thrombosis and pulmonary embolism in France over four years.

\section{Methods and results}

We reviewed all cases with a discharge diagnosis of deep vein thrombosis or pulmonary embolism entered on the national hospital discharge register between 1995 and 1998. We used the international classification of diseases, ninth and 10th revisions (deep vein thrombosis: ICD-9 codes 451.1 and 451.2 and ICD-10 codes
I80.1 and I80.2; pulmonary embolism: ICD-9 code 415.1 and ICD-10 codes I26.0 and I26.9). This dataset is a collection of all discharges from public and non-profit making, short stay, or acute hospitals in France $(71 \%$ of hospital capacity). We included discharge data if the usual confirmatory tests-or specific fibrinolytic or surgical therapy-were mentioned. Usual confirmatory tests were venography or Doppler ultrasonography for deep vein thrombosis and a ventilation and perfusion lung scan, helicoidal computed tomography, or pulmonary angiography for pulmonary embolism.

The figure shows monthly data on admissions to hospital for deep vein thrombosis $(n=65081$, median age 69 years, $58 \%$ women, $95 \%$ medical patients) and pulmonary embolism $(\mathrm{n}=62237$, median age 68 years, $57 \%$ women, $96 \%$ medical patients), presented as 


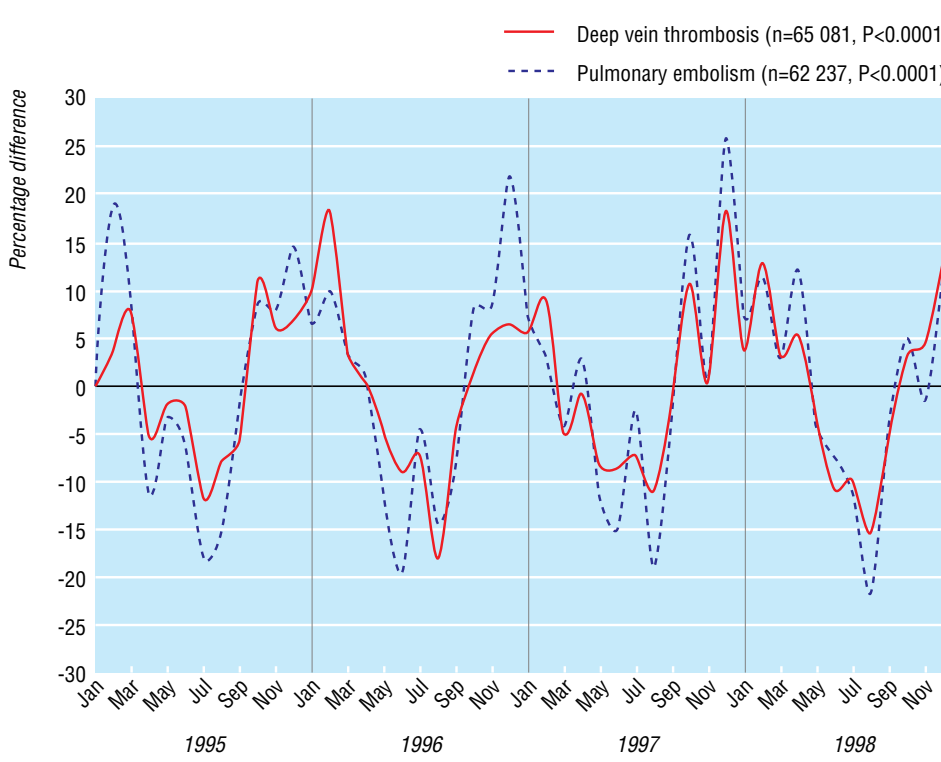

Monthly percentage variations in French hospital admissions for deep vein thrombosis and pulmonary embolism (0 represents the sum of monthly variations)

Department of Respiratory Medicine, Nice Teaching Hospital, BP 1179,06003

Nice Cédex 1 ,

France

Bruno Blaive

professor

Correspondence to: F Boulay

boulay.f@chu-nice.fr percentages above or below the average monthly value for each year of the study, the sum of monthly variations being 0 .

The number of admissions per month was significantly higher in winter and lower in summer for both deep vein thrombosis and pulmonary embolism (Roger's test': $\mathrm{P}<0.0001)$. Mean monthly admissions for deep vein thrombosis (1356 (SD 450)) ranged from 18\% below average in August 1996 to $18 \%$ above average in February 1996 and December 1997. Mean monthly admissions for pulmonary embolism (1297 (SD 268)) ranged from 22\% below average in August 1998 to $26 \%$ above average in December 1997.

The same winter predominance was observed for cases of deep vein thrombosis without confirmatory tests $(n=34245)$; cases of deep vein thrombosis without pulmonary embolism $(n=47508)$; and subgroups of deep vein thrombosis and pulmonary embolism defined by age, sex, and surgical setting (data not shown).

\section{Comment}

Clear seasonal variations exist in admission to hospital for deep vein thrombosis and pulmonary embolism. Because the study was retrospective the accuracy of diagnosis might be questioned, but any bias would be minimal as only cases with documentary proof were selected. The fact that outpatient care-recently estimated to account for a third of cases of venous thromboembolism in a community based study in France ${ }^{4}$-was not considered could be another potential source of bias. Bias would be minimal, however, as there is no reason why the decision to admit patients to hospital with deep vein thrombosis should follow a seasonal pattern. The nationwide nature of this large database also limits any selection bias from seasonal variations in populations. The fact that similar patterns occurred in different subgroups and in the admissions data for both deep vein thrombosis and pulmonary embolism also increases the credibility of these statistics.

The largest hospital series available $(n=7303)$ did not show any seasonality in deep vein thrombosis. ${ }^{2}$ The authors hypothesised that the winter predominance of deaths from pulmonary embolism could be explained by associated comorbidities, which might contribute to a reduced tolerance to small emboli. Our finding that seasonal variation exists in hospital admissions for deep vein thrombosis and pulmonary embolism suggests that thrombogenic factors could involve a seasonal component. Vasoconstriction induced by the cold and reduced physical activity produce a well documented reduction in blood flow in the lower limbs. Except for hypercoagulability, which might be induced by winter respiratory tract infections, ${ }^{5}$ little is known about seasonal fluctuations in coagulation.

We thank the Direction des Hôpitaux du Ministère de la Santé and the Centre de Traitement de l'Information du PMSI (CTIP), which maintains the databases; Ms Marie Annie Burette, Drs Michel Arenaz and Max Bensadon, and Ms Cécile Landais for helping us with data from the national hospital discharge register (PMSI); and Ms Béatrice Boureux for typing the manuscript.

Contributors: F Boulay proposed the idea of the study, acquired the data, supervised the analysis, performed the literature review, and wrote the report. F Berthier did the data analysis and helped to interpret the data, do the literature review, and write the paper. F Boulay and F Berthier will act as study guarantors for the paper. GS participated in the data analysis and contributed to the paper. CR participated in the data analysis and the literature review. YG and $\mathrm{BB}$ helped to interpret the data and review the manuscript.

Funding: None

Competing interests: None declared.

1 Allan TM, Douglas AS. Seasonal variation in deep vein thrombosis. BMJ 1996;312:1227.

2 Bounameaux H, Hicklin L, Desmarais S. Seasonal variation in deep vein thrombosis. BMJ 1996;312:284-5.

3 Roger JH. A significance test for cyclic trends in incidence data. Biometrika 1977;64:152-5.

4 Oger E. Incidence of venous thromboembolism: a community-based study in western France. EPI-GETBP Study Group. Groupe d'Etude de la Thrombose de Bretagne Occidentale. Thrombosis and Haemostasis 2000;83:657-60.

5 Woodhouse PR, Khaw KT, Plummer M, Foley A, Meade TW. Seasonal variations of plasma fibrinogen and factor VII activity in the elderly: winter infections and death from cardiovascular disease. Lancet 1994;343:435-9.

(Accepted 25 June 2001)

\section{One hundred years ago Prayer healing in Germany}

The latest fashionable form of quackery in Berlin is said to be prayer healing. This has for some time prevailed in aristocratic circles in Berlin and Potsdam, and it has also invaded the ranks of the financial aristocracy. A pharmacopœia of prayers to be used against special forms of disease has been prepared. However beneficial to patients this new method of spiritual therapeutics may be, it does not appear to be likely to enrich its professors. The practitioner of prayer healing most in vogue is a lady doctor whose fees are at the rate of 2 marks an hour.

(BMJ 1901;ii:1490) 